\title{
Percepção das mulheres em situação de violência sobre o apoio formal: Scoping review
}

\author{
Women perception in situations of violence in formal support: Scoping review \\ Percepción de las mujeres en situación de violencia en apoyo formal: Revisión de alcance
}

Marli Aparecida Rocha de Souza ${ }^{1}$ (D) Aida Maris Peres ${ }^{1}$ (1)

Lais Fumincelli ${ }^{2}$ (b)

Vagner José Lopes ${ }^{1}$ (1)

Nen NaLú Alves das Mercês ${ }^{1}$ (1)

Marilene Loewen Wall ${ }^{1}$ (1)

1. Universidade Federal do Paraná, Programa de Pós-graduação em Enfermagem. Curitiba, PR, Brasil.

2. Universidade Federal de São Carlos, Departamento de Enfermagem. São Carlos, SP, Brasil.
Autor correspondente:

Marli Aparecida Rocha de Souza.

E-mail: marlirochasouza2@gmail.com

Recebido em 02/04/2020.

Aprovado em 21/09/2020.

DOI:https://doi.org/10.1590/2177-9465-EAN-2020-0087

\section{RESUMO}

Objetivo: Examinar e mapear as evidências científicas acerca das percepções das mulheres em situação de violência quanto aos serviços de apoio social formal. Método: Scoping Review, conforme Joanna Briggs Institute e a questão norteadora: "Qual a percepção das mulheres em situação de violência ao buscar atendimento profissional nos serviços de apoio?". Inclusos estudos nacionais, internacionais, primários, abordagens qualitativas, quantitativas, métodos mistos, idiomas inglês, português e espanhol, no espaço temporal de 2014 a 2019. Realizadas buscas em sete bases de dados, encontrados 1557 artigos e selecionados 16 como amostra final. Resultados: Os atendimentos evidenciaram a escuta ativa, criação de vínculo e articulação dos serviços. Como também a falta de acolhimento; sentimento de insegurança, medo e humilhação. O processo de capacitação foi estabelecido pelos artigos como ferramenta aos profissionais, na promoção de abordagem direcionada e individualizada. Conclusões e considerações para a prática: $O$ acolhimento e vínculo propiciado por alguns serviços de apoio resultou em propostas de mudanças e suscitou nas mulheres reflexão, confiança e busca para saída do ciclo da violência. O contrário gerou afastamento dos serviços e consequente permanência junto ao agressor.

Palavras-chave: Violência contra a Mulher; Colaboração Intersetorial; Apoio Social; Revisão.

\section{ABSTRACT}

Objective: To examine and map the scientific evidence about the perceptions of women in situations of violence regarding forma social support services. Method: A Scoping Review, according to the Joanna Briggs Institute, with the following guiding question: "What is the perception of the woman in situations of violence when seeking professional assistance in support services?" Including national, international studies, primary, qualitative, quantitative approaches, mixed methods, English, Portuguese, and Spanish languages, in the period from 2014 to 2019. Searches were carried out in seven databases, 1,557 articles were found and 16 were selected as the final sample. Results: The consultations showed active listening, creating bonds and articulating services. As well as lack of reception; feeling of insecurity, fear and humiliation. The training process was established by the articles as a tool for professionals, in promoting a targeted and individualized approach. Conclusions and considerations for the practice: The welcoming and bond provided by some support services, resulted in proposals for changes and aroused in women reflection, confidence and the search for an exit from the cycle of violence. The opposite has led to removal of services and consequent permanence with the aggressor.

Keywords: Violence Against Women; Intersectoral Collaboration; Social Support; Review.

\section{RESUMEN}

Objetivo: Examinar y mapear la evidencia científica sobre las percepciones de las mujeres en situación de violencia con respecto a los servicios formales de apoyo social. Método: Revisión de alcance, según el Instituto Joanna Briggs, cuya pregunta guía fue: “¿Cuál es la percepción de las mujeres en situación de violencia cuando buscan asistencia profesional en los servicios de apoyo?". Incluye estudios nacionales, internacionales, enfoques primarios, cualitativos, cuantitativos, métodos mixtos, idiomas inglés, portugués, español, en el período de 2014 a 2019. Se realizaron búsquedas en siete bases de datos, se encontraron 1557 artículos y se seleccionaron 16 como muestra final. Resultados: Las consultas mostraron una escucha activa, creando vínculos y articulando servicios. Así como la falta de recepción; sentimiento de inseguridad, miedo y humillación. El proceso de capacitación fue establecido por los artículos como una herramienta para profesionales, en la promoción de enfoque dirigido e individualizado. Conclusiones y consideraciones para la práctica: La bienvenida y el vínculo brindado por algunos servicios de apoyo, dieron lugar a propuestas de cambios y despertaron en las mujeres la reflexión, la confianza y la búsqueda de una salida del ciclo de violencia. Lo contrario ha llevado a la eliminación de los servicios y consecuente permanencia con el agresor.

Palabras Clave: Violencia contra la Mujer; Colaboración Intersectorial; Apoyo Social; Revisión. 


\section{INTRODUÇÃO}

Mundialmente, a violência tem sido considerada um problema de saúde pública, além da violação aos direitos humanos das mulheres que se encontram vinculadas a esta situação. E na qual, a desigualdade entre homens e mulheres, principalmente a de gênero, tem no feminicídio um dos mais graves fenômenos deste contexto. E, para seu enfrentamento, algumas estratégias relacionadas à intervenção e prevenção já foram estabelecidas. ${ }^{1}$

No Brasil, a violência contra mulheres é pautada em um histórico cultural patriarcal e androcêntrico, que se constitui nessa desigualdade manifestada com a tendência a diminuir a mulher em relação ao homem, o que gera sua vulnerabilização. ${ }^{2}$ $E$ ao entender que seu enfrentamento não é somente um plano vinculado à prática profissional diária, mas à gestão desse processo, é imprescindível a utilização de diferentes estratégias, dentre elas, a criação de instituições que trabalhem de forma articulada voltadas às questões sociais e de forma intersetorial. A intersetorialidade promove a articulação entre os diversos serviços e favorece o atendimento a fenômenos $\operatorname{complexos}^{3}$ e no caso desta pesquisa, volvido às mulheres em situação de violência.

Com base nesse enfoque, o trabalho em rede ao ser realizado de forma integrada e coletiva e não somente nos contatos mais próximos, facilita a comunicação no atendimento às necessidades dessas mulheres. ${ }^{3}$ Tendo em vista que quando estas mulheres buscam por atendimento, o profissional não deve se limitar somente ao que está vendo, mas voltar seu olhar à integralidade na realização de um processo de articulação em rede, por ser a violência um fenômeno complexo e no qual um único serviço não a comporta. ${ }^{4}$

Deste modo, o preparo desses profissionais deve ocorrer de maneira a integrar em sua atuação diária, formas de enfrentamento e combate à violência ligados à articulação em rede e à resolutividade. ${ }^{4}$ Sendo que muitos serviços que compõem a rede de apoio social formal não conseguem aplicar em seu contexto de atuação meios que apoiem estas mulheres, o que fragmenta seu atendimento. ${ }^{3}$ Vinculada à insegurança do profissional e ao tema de como realizar o atendimento, incluindo a identificação da violência, já que muitas não apresentam lesões aparentes. ${ }^{5,6}$

Ponderando ainda que os profissionais que realizam esse atendimento encontram dificuldades no reconhecimento dos diversos determinantes que envolvem este fenômeno. O que impacta em atendimentos com foco na queixa, ou em julgamentos com base em pré-conceitos, tais como referências ao uso de álcool, drogas e na indecisão em continuar o processo de denúncia. $\mathrm{O}$ que deriva em não investigação a outros fatores que envolvem o contexto apresentado e como resultado, a invisibilidade da violência. ${ }^{6}$

Cabe, portanto, na implantação dessas estratégias criar um processo de capacitação, que forneça subsídios necessários a estes profissionais na atuação e intervenção de forma precoce. . $^{3,7}$ $\mathrm{Na}$ Sexagésima Assembleia Mundial realizada em maio de 2014, a resolução WHA67.15 foi proposta com foco na criação de um plano global de ação para fortalecer o papel no sistema de saúde frente a abordagem à violência interpessoal e em particular contra mulheres, meninas e crianças, tendo como um dos seus escopos o preparo profissional. ${ }^{8}$
O processo de capacitação na rede de apoio social formal aos profissionais que realizam a atenção a estas mulheres envolve, além da capacitação técnica, um olhar direcionado às suas especificidades, o que inclui o conhecimento de sua família e comunidade. A parceria entre os serviços e a comunidade deve voltar-se à autonomia e beneficiar o poder de decisão dessas mulheres, tendo em vista que não há um padrão a ser seguido, mas as melhores estratégias em um processo de intervenção com foco no protagonismo. ${ }^{9}$ Mediado pelos serviços e profissionais que fazem parte dessa rede e destacado pela literatura, como a manterem-se no desconhecimento da totalidade desse fenômeno e realização de uma prática não atualizada. ${ }^{7}$

Neste contexto, o conhecimento do que essas mulheres têm como experiência na busca aos serviços inclusos na rede de apoio social formal, tem como expectativa a promoção no direcionamento para a criação de estratégias voltadas a este atendimento, entre eles uma proposta em trabalhar processos educativos voltados a temática violência contra mulheres. O que justifica o interesse desta pesquisa e que objetiva examinar e mapear as evidências científicas acerca das percepções das mulheres em situação de violência quanto aos serviços que compõe a rede de apoio social formal.

\section{MÉTODO}

Pesquisa realizada por meio de umas das propostas do Joanna Briggs Institute (JBI) chamada de Scoping Review $(S c R)$. Trata-se de um método de revisão que pode ser realizado quando o pesquisador busca responder uma ou mais questões. É possível realizar o mapeamento abrangente de determinado tema e identificar as evidências científicas que constam na literatura, independentemente da abordagem desses estudos. ${ }^{10}$ Para assegurar o rigor na realização da $S c R$, o JBI propõe estruturas a serem utilizadas em sua condução, entre elas identificar a questão de pesquisa, identificar estudos relevantes, selecionar os estudos, organizar os dados, agrupar, sintetizar (analisar) e descrever os resultados e como opção promover uma consulta dos resultados obtidos (especialistas)..$^{10}$

Com este enfoque, a construção da questão norteadora desta revisão foi realizada por meio da estratégia Population, Concept e Context (PCC) para uma scoping review. ${ }^{10}$ Foram definidos: $P$ - mulheres em situação de violência, $C$ - especificado o atendimento que estas receberam dos profissionais da rede de apoio social formal, e C - em serviços de atenção/ enfrentamento da violência. Nesse sentido, foi estabelecida a questão norteadora: "Quais as evidências científicas acerca das percepções das mulheres em situação de violência quanto ao apoio social formal?".

Foram inclusos estudos nacionais e internacionais, com abordagens qualitativas, quantitativas e métodos mistos, provenientes de estudos primários; nos idiomas inglês, português ou espanhol; no espaço temporal de 2014 a 2019. O que veio ao encontro desta pesquisa na busca por atendimento profissional na rede de apoio social formal. Os critérios de exclusão foram estudos com temática do título e resumo que não tivesse referência à questão de revisão. 
Quanto às estratégias de busca descritas no Quadro 1, as bases de dados e fontes de informações utilizadas foram Cumulative Index to Nursing and Allied Health Literature (CINAHL), Literatura Latino-Americana e do Caribe em Ciências da Saúde (LILACS), National Library of Medicine (PubMed), SCOPUS, Embase Search Results (EMBASE), Web of Science BVS (Biblioteca Virtual em Saúde). Os descritores selecionados e sinônimos estão de acordo com os Descritores em Ciências da Saúde (DeCS): "Violência" "Saúde da Mulher"; "Violência doméstica"; "Apoio social"; "Violência contra a mulher" e no Medical Subject Headings (MeSH): "Violence" "Domestic violence" "Violence against women" "Women's health" "Social support". Para a combinação dos descritores foi considerado o operador booleano "AND" "OR", para a busca nas referidas bases de dados e plataformas de pesquisa.

As fórmulas aplicadas foram de acordo com as especificidades de cada base e dois revisores realizaram a busca no período de janeiro de 2019, no intuito de ampliar a eficácia e viabilidade na identificação e seleção dos estudos.

Para a busca e seleção das evidências científicas, foi utilizada a ferramenta PRISMA - Extension for Scoping Reviews (PRISMA$\mathrm{ScR})^{11}$, para nortear a pesquisa. Trata-se de uma ferramenta de revisão que tem como objetivo principal apoiar os revisores no registro do processo de revisões.

Os dados dos estudos selecionados, foram extraídos por meio de um instrumento estruturado pelos pesquisadores, o qual contemplou: título do estudo, autoria, periódico, ano de publicação, local do estudo (país, cidade, região), objetivo (s), detalhamento metodológico e detalhamento amostral, principais resultados e conclusões encontradas. Para as análises, os estudos foram agrupados e os resultados apresentados na forma de quadros.

\section{RESULTADOS}

A busca resultou em 1557 artigos selecionados, destes seis foram descartados por estarem duplicados nas bases de dados, restando para leitura de título e resumo 1551 artigos. Nessa nova etapa, 1117 foram excluídos, o que resultou um total de 434 artigos para seleção quanto aos critérios de inclusão e exclusão e destes, 19 artigos foram selecionados para leitura na íntegra, dos quais três foram excluídos por vinculação à interpretação dos profissionais que realizam o atendimento as mulheres em situação de violência. Na Figura 1, estão representadas o processo de busca, seleção e inclusão dos estudos selecionados, segundo ferramenta.

Nesta revisão, dos 16 estudos selecionados (100,0\%), estão distribuídos nos anos de 2014 a 2018. Destas ressaltase publicações brasileiras em $(5 / 31,25 \%)$, sendo nos anos de 2015 (1/6,2\%), em 2017 (2/12,5\%) e 2018 (1/6,2\%). Anos marcados por estratégias ao enfrentamento a violência contra mulheres. Entre elas e instituída em 2018, a Política Judiciária

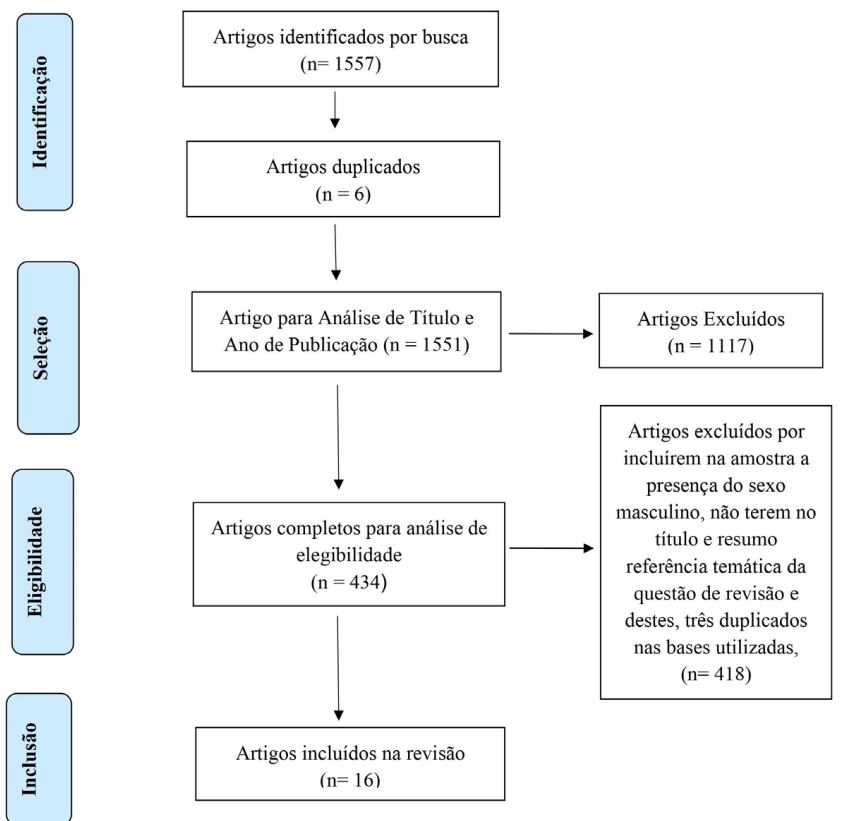

Figura 1. Processo de seleção dos artigos nas bases de dados, adaptados do PRISMA-ScR ${ }^{11}$ Curitiba, Paraná, 2019.

Quadro 1. Representação das estratégias e respectivas fórmulas de busca nas bases de dados e plataforma BVS. Curitiba, Paraná, 2019.

\begin{tabular}{|c|c|}
\hline BASE & ESTRATÉGIA \\
\hline Pubmed & $\begin{array}{l}\text { (“Violence”[Mesh]) OR “Domestic Violence”[Mesh]) AND (“Women's Health”[Mesh]) AND (“Social } \\
\text { Support”[Mesh]) }\end{array}$ \\
\hline Scopus & $\begin{array}{l}\text { (KEY(“Violence”) OR KEY (“Domestic Violence”) OR KEY(“Violence Against Women”) AND KEY(“Women's } \\
\text { Health”) AND KEY(“Social Support”)) }\end{array}$ \\
\hline Cinahl & (Violence) AND (Women's Health) AND (Social Support) \\
\hline Embase & $\begin{array}{l}\text { (Violence OR Domestic Violence OR Violence Against Women) AND (Women's Health) AND (Social } \\
\text { Support) }\end{array}$ \\
\hline Web of Science & (Violence Against Women) AND (Women's Health) AND (Social Support) \\
\hline BVS & $\begin{array}{l}\text { (Violence OR Domestic Violence OR Violence Against Women) AND (Women's Health) AND (Social } \\
\text { Support) }\end{array}$ \\
\hline
\end{tabular}


Nacional de Enfrentamento à Violência contra as Mulheres no Poder Judiciário, em que no art. 4 línea II teve a determinação de que o poder judiciário deveria dar prioridade aos processos dessa temática. ${ }^{12} \mathrm{~A}$ caracterização quanto ao ano de publicação, autores, periódico, local e método dos estudos abordado elegidos está descrita no Quadro 2.

Quanto as principais características socioeconômicas, entre os 16 estudos, $14(87,5 \%)$, a média de idade entre as mulheres variou de 12 a 81 anos. Escolaridade, 11 artigos
(68,7\%) evidenciaram o ensino médio, fundamental e superior, com destaque para o ensino médio $(31,2 \%)$ e superior $(25 \%)$. No quesito renda, $(43,7 \%)$ não evidenciaram e em seis estudos $(37,5 \%)$ prevaleceu a renda própria. Quanto a raça $(56,2 \%)$ não caracterizaram e entre os sete $(43,7 \%)$ restantes, a raça branca se sobressaiu, em quatro (25\%) dos estudos.

No Quadro 3, está descrita a amostra de cada um dos 16 estudos sobre as principais características socioeconômicas, as percepções e relatos das mulheres em situação de violência. Os

Quadro 2. Caracterização dos estudos selecionados quanto ao ano, autores, periódico publicado, local do estudo e método abordado. Curitiba, Paraná, 2019.

\begin{tabular}{|c|c|c|c|c|c|}
\hline Estudo & Ano & Autores & Periódico & Região/País & Método \\
\hline 13 & 2018 & Machisa et al. & Glob Health Action, & Gauteng, África do Sul & Quantitativo \\
\hline 14 & 2018 & Soares e Lopes & Interface & Brasil, (sem região) & Qualitativo \\
\hline 15 & 2015 & Vieira et al. & Rev. Latino-Am. Enfermagem, & Brasil, Região Sul & Qualitativo, \\
\hline 16 & 2017 & Albuquerque et al. & Texto Contexto Enferm, & Brasil, Rio de Janeiro & Qualitativo \\
\hline 17 & 2016 & Reis et al. & JCN Journal of Clinical Nursing, & Brasil, São Paulo & Qualitativo \\
\hline 18 & 2017 & Santos e Freitas & Rev Min Enferm. & Brasil, Minas Gerais & Qualitativo \\
\hline 19 & 2017 & Du Mont et al. & Plos One, & Canadá, Ontário & Quantitativo \\
\hline 20 & 2016 & Mantler e Wolfe & Rural and Remote Health, & Canadá, Ontário & Qualitativo \\
\hline 21 & 2017 & Loeffen et al. & Eur J Gen Pract, & Holanda do Sul, Roterdã & Qualitativa \\
\hline 22 & 2015 & Evans e Feder & Health Expect. 2016 & Reino Unido Região Sudoeste & Qualitativo \\
\hline 23 & 2015 & Bahrami et al. & $\begin{array}{l}\text { Global Journal of Health } \\
\text { Science, } 2016\end{array}$ & Irã, Isfahan e Shiraz & Qualitativo \\
\hline 24 & 2015 & Wuest et al. & Research in Nursing \& Health, & Canadá,New Brunswick & Métodos Mistos \\
\hline 25 & 2015 & Sprague et al. & Global Public Health, & $\begin{array}{l}\text { Africa do Sul, Joanesburgo } \\
\text { Província de Gauteng }\end{array}$ & Qualitativo \\
\hline 26 & 2014 & $\begin{array}{l}\text { Pratt- } \\
\text { Eriksson et al. }\end{array}$ & $\begin{array}{l}\text { Int J of qualitative studies on } \\
\text { Health and Well-being. }\end{array}$ & Suécia, Estocolmo & Qualitativa \\
\hline 27 & 2014 & Malpass et al. & $\begin{array}{l}\text { British Journal of General } \\
\text { Practice, }\end{array}$ & Bristol e Hackney & Qualitativa \\
\hline 28 & 2014 & Ekström & European Journal of Social, & Estocolmo & Qualitativa \\
\hline
\end{tabular}

Quadro 3. Descrição da amostra dos estudos quanto ao tipo de violência relatada pelas mulheres. Curitiba, Paraná, 2019.

\begin{tabular}{|cll|}
\hline Estudo & \multicolumn{1}{c}{ Percepções das mulheres participantes } & Violência relatada \\
\hline 13 & $\begin{array}{l}\text { O apoio social gerou maior resiliência e promoveu a busca para saída do ciclo por meio da } \\
\text { mobilização de recursos necessários, gerando busca aos serviços formais e dar continuidade. }\end{array}$ & Física ou sexual \\
14 & $\begin{array}{l}\text { A primeira opção no atendimento foi o tratamento medicamentoso; Profissional não gerou } \\
\text { acolhimento ou demonstrou interesse em ouvir; O atendimento gerou vergonha pela } \\
\text { violência sofrida e não retorno ao serviço para dar continuidade. }\end{array}$ & $\begin{array}{l}\text { Violência nas } \\
\text { relações }\end{array}$ \\
15 & Atendimento impessoal nos serviços de saúde; & $\begin{array}{l}\text { Psicológica, física e } \\
\text { moral. }\end{array}$ \\
16 & $\begin{array}{l}\text { Criação de vínculo com o profissional, e os encaminhamentos e suporte foram adequados } \\
\text { nas necessidades imediatas e futuras. Já os serviços de saúde geraram desistência da } \\
\text { denúncia. }\end{array}$ & $\begin{array}{l}\text { Física, psicológica, } \\
\text { sexual, moral ou } \\
\text { patrimonial }\end{array}$ \\
\hline
\end{tabular}


Quadro 3. Continuação...

\begin{tabular}{|c|c|c|}
\hline Estudo & Percepções das mulheres participantes & Violência relatada \\
\hline 17 & $\begin{array}{l}\text { Atendimento multiprofissional focou necessidades físicas, psicológicas e as sociais. Já o } \\
\text { serviço policial gerou descaso e sentimento de responsabilidade pelo ocorrido. }\end{array}$ & Sexual \\
\hline 18 & $\begin{array}{l}\text { Não resolutividade, descaso, sensação de que deveriam permanecer com agressor. E, } \\
\text { quando acolhidas, se sentiram encorajadas e apoiadas ao enfrentamento da situação. }\end{array}$ & $\begin{array}{l}\text { Física, sexual, } \\
\text { psicológico, } \\
\text { comportamentos } \\
\text { controladores. }\end{array}$ \\
\hline 19 & Adequado e houve divulgação do serviço para outras mulheres. & Violência sexual \\
\hline 20 & $\begin{array}{l}\text { Profissional gerou atenção além da função e auxílio nas necessidades e não precisaram } \\
\text { contar suas histórias mais de uma vez. }\end{array}$ & $\begin{array}{l}\text { Violência proferida } \\
\text { por parceiro íntimo }\end{array}$ \\
\hline 21 & $\begin{array}{l}\text { Tiveram confiança ao falar e foram ouvidas, o que gerou bem-estar e fortalecimento para } \\
\text { continuar. }\end{array}$ & $\begin{array}{l}\text { Violência por } \\
\text { parceiro íntimo }\end{array}$ \\
\hline 22 & $\begin{array}{l}\text { Atendimento focado em medicamento e sentiram que isso não resolveria o problema, pois } \\
\text { sabiam que o problema estava na relação com o parceiro. }\end{array}$ & Violência doméstica \\
\hline 23 & $\begin{array}{l}\text { Ao serem ouvidas refletiram sobre sua condição atual em busca de soluções; E quando não } \\
\text { foram ouvidas promoveu sensação de impunidade quanto a violência sofrida. }\end{array}$ & $\begin{array}{l}\text { Psicológica, Sexual, } \\
\text { Moral, Física e } \\
\text { Patrimonial }\end{array}$ \\
\hline 24 & $\begin{array}{l}\text { Direcionamento e encaminhamentos conforme às necessidades, sensação de conforto e } \\
\text { apoio. }\end{array}$ & Foco na sexual \\
\hline 25 & $\begin{array}{l}\text { Não se sentiram à vontade para conversar com outros profissionais, por saberem o que } \\
\text { iriam falar sobre o fato. }\end{array}$ & Por parceiro íntimo \\
\hline 26 & $\begin{array}{l}\text { Serviços desarticulados, frustação pelo arquivamento dos casos. Culpa, humilhadas ao } \\
\text { terem que agradecer o atendimento recebido. }\end{array}$ & Foco na sexual \\
\hline 27 & $\begin{array}{l}\text { Alívio pelo auxílio e direcionamento na situação apresentada e à vontade ao falar e ser } \\
\text { ouvida, sem sentimento de culpa pelo fato. }\end{array}$ & $\begin{array}{l}\text { Física, emocional, } \\
\text { verbal, sexual, } \\
\text { financeira }\end{array}$ \\
\hline 28 & $\begin{array}{l}\text { Impunidade e sem informação sobre o que iria acontecer, pressionadas, não ouvidas. Em } \\
\text { alguns serviços direcionadas e acolhidas. }\end{array}$ & $\begin{array}{l}\text { Foco na sexual e } \\
\text { física. }\end{array}$ \\
\hline
\end{tabular}

principais resultados quanto ao tipo de serviço e atendimento profissional na percepção das mulheres em situação de violência estão descritos no Quadro 3.

Em relação a busca pelos serviços de saúde, os estudos apresentaram: Serviço médico ou psicossocial, e rede de apoio social formal ao atendimento as mulheres em situação de violência, unidade básica de saúde (UBS), delegacia de polícia (DP) e delegacia polícia de atendimento à mulher (DEAM), Centro de referência de Atendimento à Mulher (CRAM), Ministério Público (MP), conselho tutelar e psicológico, casa abrigo, Instituto Médico Legal (IML), pronto atendimento de urgência, hospital, terceiro setor (igrejas e organização não governamental), fóruns, escolas, assistência social (AS), centro especializado de tratamento de violência sexual, clínica forense e centros de aconselhamentos e discutidos o que uma teve como participação no atendimento $e$ quanto a percepção sobre o profissional e principais conclusões no Quadro 4.

O Quadro 5, representa os relatos das mulheres em situação de violência, após serem atendidas pelos profissionais nos serviços de apoio formal. Alguns apresentam fragilidades e outros fragilidades e potencialidades, bem como o que cada um representou para elas.

\section{DISCUSSÃO}

Após a análise dos estudos, algumas características ficaram evidentes tais como: a média de idade de 41 anos, a raça variou entre negra, parda, branca e indígena. Quanto a raça e etnia, $43,7 \%^{13-15,17,20,21,23,24}$ não as destacaram e 56,2\%, ${ }^{14,16,18,19,22,25-28}$ classificaram raça ou etnia, porém não relacionaram com a violência. O que foi encontrado em um estudo de 2019, no qual idade, raça ou cor, não apresentaram relação de maior possibilidade das mulheres em sofrerem violência, mas a relação entre as mulheres com menor nível de escolaridade, e menor número de filhos. ${ }^{29}$

Nesta pesquisa, 10 estudos $(62,5 \%)^{13-16,18,21,23-26}$ destacaram o nível de escolaridade, com prevalência do médio e fundamental e em oito o superior (80\%). Os demais $37,5 \% \%^{16,18,19,21,26,27}$ não 
Quadro 4. Resultados dos 16 artigos referentes ao atendimento profissional na percepção das mulheres em situação de violência. Curitiba, Paraná, 2019.

\begin{tabular}{|c|c|c|c|c|}
\hline Estudo & $\begin{array}{c}\text { Tipo de serviço de apoio } \\
\text { social formal }\end{array}$ & $\begin{array}{l}\text { Atendimento e categoria } \\
\text { profissional }\end{array}$ & Principais Resultados & Principais Conclusões \\
\hline 13 & Médico ou psicossocial. & $\begin{array}{l}\text { Análise quantitativa, sem } \\
\text { relatos. }\end{array}$ & $\begin{array}{l}\text { Abusos mais graves e } \\
\text { dificuldade no acesso } \\
\text { geram menor busca aos } \\
\text { serviços. }\end{array}$ & $\begin{array}{l}\text { Serviços formais que } \\
\text { tiveram foco em sintomas } \\
\text { gerou menor resiliência. }\end{array}$ \\
\hline 14 & $\begin{array}{l}\text { UBS, Delegacia, CRAM, } \\
\text { MP, }\end{array}$ & $\begin{array}{l}\text { No CRAM bom } \\
\text { atendimento; Saúde: } \\
\text { Médico focou } \\
\text { medicamentos e não } \\
\text { forneceu orientação e a } \\
\text { enfermeira foi ríspida; } \\
\text { Delegacia: Falta de apoio; } \\
\text { MP: falta de segurança; } \\
\text { Juíza: Falta de informação } \\
\text { e indução para falarem; }\end{array}$ & $\begin{array}{l}\text { Positivas: Ao serem } \\
\text { acolhidas promoveu } \\
\text { satisfação e vínculo; } \\
\text { Negativas: Foco } \\
\text { na doença, falta } \\
\text { de: orientação, de } \\
\text { acolhimento e vínculo, } \\
\text { gerando vergonha e culpa. }\end{array}$ & $\begin{array}{l}\text { Foco em doença, } \\
\text { falta de acolhimento } \\
\text { e desconhecimento } \\
\text { gerou: medo, vergonha } \\
\text { e julgamento; Alguns } \\
\text { forneceram atendimento } \\
\text { adequado. }\end{array}$ \\
\hline 15 & $\begin{array}{l}\text { DEAM, CT, escola, PM, } \\
\text { UBS, IML, MP, Serviço } \\
\text { móvel de urgência, PA, } \\
\text { psiquiátrico, Igreja; ONGs, } \\
\text { jurídico, psicologia. }\end{array}$ & $\begin{array}{l}\text { Na rede formal secundária } \\
\text { apresentou: falta de } \\
\text { vínculo e de confiança e } \\
\text { o profissional da saúde } \\
\text { gerou fragilidade no } \\
\text { atendimento. }\end{array}$ & $\begin{array}{l}\text { O foco foi na doença; } \\
\text { Além de falta de } \\
\text { orientação, de } \\
\text { acolhimento e de vínculo } \\
\text { o que gerou vergonha, } \\
\text { culpa e a não procura } \\
\text { aos serviços, mesmo na } \\
\text { presença de lesões físicas. }\end{array}$ & $\begin{array}{l}\text { A rede formal não } \\
\text { promoveu meios } \\
\text { para saída do ciclo, } \\
\text { demonstrado } \\
\text { intersetorialidade; } \\
\text { E a falta de foco } \\
\text { na integralidade, } \\
\text { gerou afastamento e } \\
\text { permanência com os } \\
\text { agressores. }\end{array}$ \\
\hline 16 & $\begin{array}{l}\text { Hospitais, postos de } \\
\text { saúde, DEAM, centros de } \\
\text { atendimento e fóruns, } \\
\text { escolas, AS, justiça. }\end{array}$ & $\begin{array}{l}\text { Enfermeira (UBS) gerou } \\
\text { vínculo e direcionamento, } \\
\text { médicos, advogados e } \\
\text { defensores públicos foram } \\
\text { sensíveis e preocupados. } \\
\text { E A.S. e psicóloga geraram } \\
\text { acolhimento, conforto. } \\
\text { Bem como professores } \\
\text { promoveram auxílio. Mas } \\
\text { também locais que na } \\
\text { saúde gerou silêncio nas } \\
\text { mulheres; }\end{array}$ & $\begin{array}{l}\text { A rede formal secundária } \\
\text { vista como fonte de } \\
\text { apoio. E o vínculo } \\
\text { permitiu conhecer a } \\
\text { origem das queixas, apoio } \\
\text { e encaminhamento, } \\
\text { adequado. O contrário } \\
\text { gerou desistência na } \\
\text { denúncia. }\end{array}$ & $\begin{array}{l}\text { Interação entre serviços } \\
\text { gerou assistência } \\
\text { efetiva e vínculo, } \\
\text { destaque nas Escolas, } \\
\text { UBS, DEAMs e CEAMs, } \\
\text { e direcionamentos } \\
\text { adequados gerou } \\
\text { afastamento do agressor. } \\
\text { Mas quanto tiveram } \\
\text { insegurança gerou o } \\
\text { afastamento do serviço. }\end{array}$ \\
\hline 17 & Hospitais e DEAM. & $\begin{array}{l}\text { Advogado, enfermeiras } \\
\text { e médicos com apoio e } \\
\text { direcionamento; porém } \\
\text { os Policiais geraram } \\
\text { humilhação, falta de apoio } \\
\text { e culpa. }\end{array}$ & $\begin{array}{l}\text { O vínculo criado permitiu } \\
\text { apoio, conhecer a } \\
\text { origem das queixas } \\
\text { e encaminhamento } \\
\text { adequado. Quando } \\
\text { não houve acolhimento } \\
\text { e escuta gerou culpa } \\
\text { humilhação. }\end{array}$ & $\begin{array}{l}\text { Experiências negativas } \\
\text { com DP como sentimento } \\
\text { de humilhação, falta de } \\
\text { apoio e intimidação. } \\
\text { Porém quando } \\
\text { criado vínculo gerou } \\
\text { encaminhamento } \\
\text { multiprofissional nas } \\
\text { necessidades. }\end{array}$ \\
\hline
\end{tabular}


Quadro 4. Continuação...

\begin{tabular}{|c|c|c|c|c|}
\hline Estudo & $\begin{array}{l}\text { Tipo de serviço de apoio } \\
\text { social formal }\end{array}$ & $\begin{array}{l}\text { Atendimento e categoria } \\
\text { profissional }\end{array}$ & Principais Resultados & Principais Conclusões \\
\hline 18 & $\begin{array}{l}\text { IML, DP, Posto de saúde } \\
\text { (PS), CRAM }\end{array}$ & $\begin{array}{l}\text { Na DM: falta de } \\
\text { informação; No PS: } \\
\text { falta de sigilo e ética e } \\
\text { sentimento de inverdade } \\
\text { ao relato feito; Psicóloga } \\
\text { (UBS) não acolheu e } \\
\text { o Médico foi rude e } \\
\text { no CRAM a psicóloga } \\
\text { promoveu apoio. }\end{array}$ & $\begin{array}{l}\text { Apresentado } \\
\text { desarticulação dos } \\
\text { serviços: alguns sem } \\
\text { encaminhamentos, } \\
\text { Informação, acolhimento } \\
\text { e humanização; Outros } \\
\text { com acolhimento, apoio e } \\
\text { confiança; }\end{array}$ & $\begin{array}{l}\text { Falta de preparo } \\
\text { profissional, apoio e } \\
\text { acolhimento, aliado } \\
\text { a fragmentação } \\
\text { levou as mulheres a } \\
\text { terem insegurança. O } \\
\text { contrário fortaleceu o } \\
\text { enfrentamento a situação. }\end{array}$ \\
\hline 19 & $\begin{array}{l}\text { Centro especializado em } \\
\text { violência sexual. }\end{array}$ & $\begin{array}{l}\text { Adequados atendimentos } \\
\text { dos profissionais. }\end{array}$ & $\begin{array}{l}\text { Pelo atendimento as } \\
\text { mulheres queriam } \\
\text { divulgar os serviços para } \\
\text { outras. }\end{array}$ & $\begin{array}{l}\text { Satisfação com o } \\
\text { atendimento e o serviço. }\end{array}$ \\
\hline 20 & $\begin{array}{l}\text { Abrigo especializado em } \\
\text { atendimento a mulheres. }\end{array}$ & $\begin{array}{l}\text { O olhar além da situação } \\
\text { gerou satisfação e } \\
\text { profissional criou vínculo } \\
\text { e confiança, e facilitou } \\
\text { acesso a outro serviço. }\end{array}$ & $\begin{array}{l}\text { O acolhimento } \\
\text { gerou confiança e o } \\
\text { direcionamento gerou } \\
\text { satisfação, pelo foco nas } \\
\text { necessidades. }\end{array}$ & $\begin{array}{l}\text { A integração dos serviços } \\
\text { promoveu acolhimento, } \\
\text { escuta adequada e foco } \\
\text { nas necessidades. }\end{array}$ \\
\hline 21 & $\begin{array}{l}\text { Unidade de atendimento } \\
\text { na atenção primária as } \\
\text { mulheres que sofreram } \\
\text { VPI. }\end{array}$ & $\begin{array}{l}\text { Profissionais capacitados } \\
\text { proporcionaram quebra } \\
\text { de barreiras e vínculo. } \\
\text { Mas o profissional médico } \\
\text { criou barreiras. }\end{array}$ & $\begin{array}{l}\text { Alguns profissionais } \\
\text { geraram confiança, } \\
\text { abertura e quererem } \\
\text { continuar o processo. } \\
\text { Outros criaram barreira } \\
\text { e não identificaram as } \\
\text { necessidades. }\end{array}$ & $\begin{array}{l}\text { A capacitação } \\
\text { dos profissionais } \\
\text { gerou melhores } \\
\text { direcionamentos e } \\
\text { articulação nos serviços } \\
\text { e nas mulheres melhor } \\
\text { enfrentamento. }\end{array}$ \\
\hline 22 & $\begin{array}{l}\text { Conselho psicológico } \\
\text { e agência de moradia } \\
\text { segura Atenção primária }\end{array}$ & $\begin{array}{l}\text { O psicólogo: Gerou } \\
\text { percepção do abuso de } \\
\text { si e o presente em seu } \\
\text { entorno; O médico (AP) } \\
\text { demonstrou que contar o } \\
\text { fato foi inútil; }\end{array}$ & $\begin{array}{l}\text { A escuta ativa gerou } \\
\text { autorreflexão. Mas } \\
\text { inibição ao serem } \\
\text { atendidas pelo sexo } \\
\text { masculino; E o médico } \\
\text { teve foco na doença. }\end{array}$ & $\begin{array}{l}\text { O apoio gerou reflexão } \\
\text { da relação de violência } \\
\text { e melhor avaliação das } \\
\text { decisões a serem tomadas } \\
\text { quanto ao fato. }\end{array}$ \\
\hline 23 & $\begin{array}{l}\text { Centros de saúde, clínicas } \\
\text { forenses, centro de } \\
\text { aconselhamento e DP }\end{array}$ & $\begin{array}{l}\text { As ações sugeridas } \\
\text { pelos profissionais, não } \\
\text { conseguiam realizar } \\
\text { e gerou culpa. Mas } \\
\text { ao serem acolhidas } \\
\text { e apoiadas gerou } \\
\text { autorreflexão. DP gerou } \\
\text { sensação de impunidade, } \\
\text { ao ouvir a queixa prender } \\
\text { e liberar o agressor. }\end{array}$ & $\begin{array}{l}\text { A escuta, apoio e } \\
\text { direcionamento } \\
\text { promoveu } \\
\text { empoderamento e a } \\
\text { autoconfiança levou a } \\
\text { buscarem formas de } \\
\text { superação. O contrário } \\
\text { levou a permanecerem na } \\
\text { relação de violência. }\end{array}$ & $\begin{array}{l}\text { Os modelos de } \\
\text { enfrentamento que as } \\
\text { mulheres apresentam } \\
\text { devem ser considerados, } \\
\text { o profissional deve ser } \\
\text { preparado em sua prática } \\
\text { diária para acolher de } \\
\text { formas diferentes cada } \\
\text { situação. }\end{array}$ \\
\hline 24 & $\begin{array}{l}\text { Atenção primária saúde } \\
\text { (APS) e serviço vinculado } \\
\text { ao atendimento. }\end{array}$ & $\begin{array}{l}\text { Enfermeira (APS) } \\
\text { promoveu assistência } \\
\text { à saúde ao atuar em } \\
\text { parceria com outro } \\
\text { profissional do serviço. }\end{array}$ & $\begin{array}{l}\text { Profissionais que foram } \\
\text { capacitados, promoveram } \\
\text { ações que levaram a } \\
\text { satisfação por saberem } \\
\text { como deveriam realizá- } \\
\text { las. }\end{array}$ & $\begin{array}{l}\text { Promover vínculo e } \\
\text { integração levaram } \\
\text { ao encaminhamento } \\
\text { e fortalecimento } \\
\text { das mulheres na } \\
\text { integralidade. }\end{array}$ \\
\hline
\end{tabular}


Quadro 4. Continuação...

\begin{tabular}{|c|c|c|c|c|}
\hline Estudo & $\begin{array}{c}\text { Tipo de serviço de apoio } \\
\text { social formal }\end{array}$ & $\begin{array}{l}\text { Atendimento e categoria } \\
\text { profissional }\end{array}$ & Principais Resultados & Principais Conclusões \\
\hline 25 & $\begin{array}{l}\text { Serviço de atendimento a } \\
\text { mulheres. }\end{array}$ & $\begin{array}{l}\text { As enfermeiras fizeram } \\
\text { piada, com nome } \\
\text { pejorativo após o } \\
\text { atendimento. }\end{array}$ & $\begin{array}{l}\text { A exposição gerada levou } \\
\text { a busca por serviços } \\
\text { particulares. }\end{array}$ & $\begin{array}{l}\text { Não acolher gera } \\
\text { afastamento, e a } \\
\text { Capacitação ao } \\
\text { acolhimento. }\end{array}$ \\
\hline 26 & Abrigo para mulheres & $\begin{array}{l}\text { Médicos foram } \\
\text { rudes e com foco na } \\
\text { doença e as perguntas } \\
\text { causaram humilhação } \\
\text { e constrangimento. } \\
\text { Bem como o AS gerou } \\
\text { humilhação }\end{array}$ & $\begin{array}{l}\text { Sentimento de culpa, } \\
\text { vergonha, além do } \\
\text { não atendimento às } \\
\text { necessidades e a figura } \\
\text { masculina causaram } \\
\text { constrangimento. }\end{array}$ & $\begin{array}{l}\text { Desconhecimento } \\
\text { profissional sobre } \\
\text { a temática, gera } \\
\text { desesperança, culpa } \\
\text { insegurança, frustação e } \\
\text { invisibilidade da violência } \\
\text { sofrida. }\end{array}$ \\
\hline 27 & $\begin{array}{l}\text { AP, Advocacia à Mulheres } \\
\text { em DVA. }\end{array}$ & $\begin{array}{l}\text { Médica (o): escutou } \\
\text { e gerou esperança; } \\
\text { Advogado: gentil, } \\
\text { atencioso e encaminhou. }\end{array}$ & $\begin{array}{l}\text { A integração dos serviços } \\
\text { gerou encaminhamento } \\
\text { e profissional capacitado } \\
\text { gerou autorreflexão. }\end{array}$ & $\begin{array}{l}\text { Encaminhamentos } \\
\text { adequados geram } \\
\text { confiança e tomada de } \\
\text { decisão para saída do } \\
\text { ciclo. }\end{array}$ \\
\hline 28 & $\begin{array}{l}\text { Centro de apoio de } \\
\text { assistentes sociais }\end{array}$ & $\begin{array}{l}\text { Polícia: solidão, falta de } \\
\text { informação, silêncio e } \\
\text { querer retirar a queixa. } \\
\text { AS: apoio e segurança. }\end{array}$ & $\begin{array}{l}\text { Fragilidade nas } \\
\text { informações, pressão e } \\
\text { insegurança. Acolhimento } \\
\text { levou apoio e segurança. }\end{array}$ & $\begin{array}{l}\text { Profissionais capacitados } \\
\text { geraram melhor } \\
\text { direcionamento no } \\
\text { processo de mudança } \\
\text { para estas mulheres. }\end{array}$ \\
\hline
\end{tabular}

Quadro 5. Temas que se destacaram nos estudos selecionados e presentes nas falas das mulheres, após atendimento nos serviços formais. Curitiba, Paraná, 2019.

\begin{tabular}{|lcl|}
\hline \multicolumn{1}{|c|}{ Palavras chaves evidenciadas } & Estudos relacionados & \multicolumn{1}{c|}{ Características } \\
\hline $\begin{array}{l}\text { Foco na doença e não nas necessidades } \\
\text { das mulheres. }\end{array}$ & $13-16,25$ & $\begin{array}{l}\text { Atendimento na busca imediata e não a longo prazo, } \\
\text { resultando não procura posterior. }\end{array}$ \\
$\begin{array}{l}\text { Desarticulação, falta de vínculo, } \\
\text { informação, apoio e de acolhimento. }\end{array}$ & $14-18,25,28$ & $\begin{array}{l}\text { Divergências entre o atendimento profissional com } \\
\text { destaque a falta de intersetorialidade e a desesperança } \\
\text { nos serviços formais. }\end{array}$ \\
$\begin{array}{l}\text { Acolhimento, apoio, encaminhamentos, } \\
\text { confiança, foco nas necessidades e } \\
\text { autorreflexão }\end{array}$ & $14,16-25,27,28$ & $\begin{array}{l}\text { Ações classificadas como potencialidades geraram } \\
\text { autoconfiança e reflexão sobre o contexto vivenciado e } \\
\text { em alguns casos gerou a saída da convivência junto ao } \\
\text { agressor. }\end{array}$ \\
$\begin{array}{l}\text { Medo, vergonha, insegurança, } \\
\text { humilhação, constrangimento e culpa. }\end{array}$ & $14,15,17,18,25,26,28$ & $\begin{array}{l}\text { Situações que promoveram afastamento destas } \\
\text { mulheres aos serviços e volta ao contexto de violência. }\end{array}$ \\
\hline
\end{tabular}

classificaram. Em sete $(43,7 \%)^{14-16,18,19,23,25}$ destacou-se a renda própria das mulheres, em contrapartida a não renda pode ser um inibidor para a saída das mulheres da relação, pelo medo em não conseguirem manter-se, ou a seus filhos. E, destaque em um estudo em Istambul, ${ }^{30}$ onde o risco para o aumento da violência doméstica foi relacionado ao menor índice de renda familiar, a não inserção das mulheres no mercado de trabalho e não permissão pelo companheiro.

E que se dá, pelo encontro das ideias do controle e poder do homem sobre a autonomia das mulheres e no aumento da violência nas que se inserem no mercado de trabalho, assim em alguns momentos é gerador da violência e em outro impulsiona à saída, pela conquista de autonomia financeira. ${ }^{30}$ Nesta pesquisa, se constatou a tendência de mulheres com menor renda sofrerem mais violência, todavia, outras análises são necessárias, pelo baixo percentual na diferença.

Um dos estudos destacou enfermeiras que realizam atendimento às mulheres em situação de violência e que sofriam violência doméstica e que não buscaram atendimento no local de trabalho, por se sentirem-se constrangidas e discriminadas pelo 
não sigilo por parte dos profissionais. A situação vivenciada na situação de violência, promoveu maior foco em sua atuação para criar vínculo e entender a origem da violência sofrida por outras mulheres. ${ }^{25} \mathrm{O}$ que vem ao encontro da importância do preparo profissional na atenção a estas mulheres, não pela vivência, mas pelo reconhecimento da importância dessa temática.

O desconhecimento gera despreparo e acarreta atendimento voltado a questões fisiológicas e não à necessidade real, nem sempre verbalizada pelas mulheres na busca aos serviços. No entanto, a capacitação não pode ser vista como uma situação isolada, mas vinculada a uma cultura, na qual exista como meta a educação permanente aplicada de forma a tornar-se uma política institucional a ser mantida e perpetuada. ${ }^{31}$

O acolhimento e vínculo, quando realizados, foram destacados por gerar satisfação e reflexão sobre si e no contexto de inserção, em contrapartida, quando não provocou insatisfação, desesperança, medo, vergonha, humilhação e culpa. E esteve vinculado à uma fragilidade nos estudos, ${ }^{14-18,25}$ associado a divergência profissional e falta de informação. ${ }^{28} \mathrm{O}$ acolhimento é um passo primordial ligado a percepção das necessidades biológicas, social e psicológica e criação de vínculo, no intuito de entender a situação em sua integralidade, promover segurança e apoio. ${ }^{31}$

Nos estudos ${ }^{14,15}$, foi demonstrado que a experiência das mulheres ao serem atendidas por profissionais ligados aos serviços de colaboração intersetorial e que não geraram vínculo, motivou decisão de não retorno, mesmo em casos de lesões físicas. A literatura demonstrou que profissionais que realizam o atendimento na rede de colaboração intersetorial voltada a violência contra mulheres, demonstram desarticulação, fragilidade dos serviços e no apoio às necessidades individuais das mulheres em situação de violência. ${ }^{24}$ Fato que condiz aos achados desta pesquisa.

Um dos estudo ${ }^{20}$ destacou a importância na construção de relacionamentos, conexão efetiva dos serviços, mobilização da comunidade com educação em saúde e conscientização da realização de um trabalho intersetorial. Outros ${ }^{13,15}$ que atendimento superficial ou reducionista, pode gerar a não procura destas mulheres, principalmente na dificuldade de acesso aos serviços. Deve-se levar em conta que a barreira nem sempre é quebrada de imediato, desta forma o vínculo pode garantir continuidade ao atendimento. Nos estudos ${ }^{19,28}$ em que o acolhimento e vínculo foram realizados, favoreceu o relato e melhores encaminhamentos. Em oposição, os que não o fizeram impactou em fragilidade, constrangimento e sentimento de pressão quanto aos relatos, mesmo quando apresentavam dificuldade e insegurança na verbalização. ${ }^{18,28}$

Além de que muitas mulheres não refletem em seu contexto de inserção, por estarem habituadas a essa forma de se relacionar com alguém, se sentem culpadas, conforme os estudos. ${ }^{22,26}$ Destaque no estudo ${ }^{22}$ de que esta forma de perceber seu contexto, determina o conviver com a violência como única opção e não conseguem estabelecer confiança necessária em partilhar informações. E entendem que divulgar o fato, pode causar prejuízo com o agressor, caso tome conhecimento, ou perder o direito de conviver com os filhos, o que leva a busca por pessoas próximas e que nem sempre conseguem direcioná-las. $\mathrm{E}$, quando o fazem, o atendimento se restringe à medicalização e à doença, destacado nos estudos. ${ }^{14,15,26}$

O que colabora para que retornem ao contexto de violência e perde-se a oportunidade de saída, como visto no estudo ${ }^{14}$ é importante que haja corresponsabilização e auxílio dos profissionais que fazem parte da rede de colaboração intersetorial na tomada de decisão, na promoção de informações adequadas ao seu empoderamento. ${ }^{15}$ É importante salientar que a avaliação do subjetivo não desconsidera a condição física, mas valoriza a busca da compreensão e continuidade do processo de autonomia dessas mulheres. ${ }^{15,16}$ Tendo em vista que o sentimento de merecedoras da agressão foi enfatizado em um dos estudos ${ }^{26}$ ao terem a percepção de atendimentos com desrespeito, incompreensão, humilhação, invisibilidade e o reviver a violência sofrida, e como consequência a não procura e descrédito nos serviços.

Em oposição a essa forma de atendimento, um dos estudos ${ }^{19}$ destacou que ao identificar essas situações, promover vínculo, oferecer apoio e direcionamento adequado, gerou bem-estar e busca para mudar na condição atual. Destarte, um atendimento pautado no acolhimento, escuta ativa, apoio e articulação dos serviços, beneficia a estas mulheres estratégias de mudanças. Bem como a capacitação quando promovida como forma de melhorar a abordagem e direcionamento, e realçado como a gerar tomada de decisão e fortalecimento na continuidade no processo de mudança. Igualmente, a articulação entre os serviços, gerou suporte nos tratamentos de forma integral. ${ }^{16,24} \mathrm{O}$ que não ocorre quando os profissionais têm uma visão limitada ou desconhecem a temática e seu contexto cultural.

Deste modo promover meios em que o profissional tenha segurança no atendimento, gera conhecimento para realizar perguntas direcionadas na busca a origem da situação apresentada. $\mathrm{E}$, ao falarem sobre si, estas mulheres podem refletir o contexto da relação e os motivos que a fizeram procurar os serviços e permitir que o profissional trace um plano individual, com foco nas necessidades a curto e a longo prazo. ${ }^{31-33} \mathrm{~A}$ obtenção de saberes sobre cada situação, favorece aos serviços de colaboração intersetorial, um encaminhamento apropriado à necessidade individual, o contrário causa sentimento de falta de resolutividade. Tal fato, otimiza o tempo das mulheres ao percorrerem estes serviços e irão focar seu tempo em uma atenção centrada. Fato evidenciado nos estudos, ${ }^{16,17,19-24,27,28}$ nos quais o atendimento realizado por profissionais com o foco em acolher, ouvir e direcionar, tornaram-se impulsionadores para que estas mulheres continuassem a busca em resolutividade e posterior afastamento do agressor.

\section{CONSIDERAÇÕES FINAIS}

A percepção das mulheres sobre $o$ atendimento profissional ao sofrerem alguma forma de violência teve entre os resultados desta pesquisa o destaque à falta de vínculo, ao acolhimento e à desarticulação em rede. Em contraposição, os relatos ressaltaram 
que, quando a rede de apoio formal esteve vinculada a serviços de colaboração intersetorial e priorizou o atendimento e incluiu métodos que permitiram autorreflexão, suscitando nas mulheres a busca por mudanças.

Nos estudos analisados, sobressaíram relatos de sentimento de culpa, vergonha, insegurança, não resolutividade, impunidade, desconforto e humilhação, em paralelo ao desconhecimento na abordagem do tema violência e no modelo reducionista voltado às lesões aparentes, à doença e à medicalização. E que remete ao modelo biomédico, no qual a parte biológica é valorizada, sem enfoque na subjetividade das mulheres e suas necessidades específicas, nem sempre evidentes em uma primeira abordagem. $\mathrm{E}$, apesar do atendimento com foco no acolhimento e exercício da escuta ativa é frequentemente divulgado no meio científico, e evidenciado nesta pesquisa, que não é uma realidade praticada em todos os serviços, ou por todos os profissionais na rede de apoio social formal, além de conforme analisado, promove o afastamento destas mulheres ou a não adesão ao plano de tratamento.

Apesar da evidência de que a capacitação promove resolutividade, esta não foi abordada em sua totalidade nos estudos como estratégia ao enfrentamento a violência contra mulheres. A capacitação é um processo que não pode ser desvinculado ao atendimento, porém nota-se que, mesmo existindo políticas específicas e frequentemente realizadas nos serviços de saúde, ainda é uma fragilidade. Sugerem-se pesquisas que evidenciem quais pontos são necessários na prática cotidiana, para que o atendimento fortaleça a autonomia das mulheres e as apoie com ferramentas necessárias as tomadas de decisão e saída do ciclo de violência em que se encontram.

As contribuições desta pesquisa, e encontradas na $S c R$, são as de que nos serviços em que os processos educativos foram ponto comum, as mulheres tiveram como reflexo a percepção de um atendimento com melhores direcionamentos e autorreflexão. Mas também uma lacuna evidenciada, principalmente referente a temática violência em suas vertentes e que podem ser estratégias utilizadas nesse enfrentamento. Sugere-se que novos estudos foquem em estratégias utilizadas e temáticas abordadas, além dos fluxos e técnicas diárias nos processos educativos voltados a um contexto histórico social e questões de gênero e ainda incipientes aos que atendem as mulheres em situação de violência e refletidos nesta pesquisa, pela percepção das mulheres ao buscarem estes serviços.

\section{CONTRIBUIÇÕES DOS AUTORES}

Concepção do projeto, busca de dados e seleção dos estudos, redação do projeto, análise e interpretação dos dados. Marli Aparecida Rocha de Souza.

Concepção do projeto, desenho da revisão, seleção dos estudos, revisão crítica do conteúdo intelectual, discussão dos achados e aprovação final. Aida Maris Peres.

Desenho da revisão, redação do projeto, discussão dos achados, revisão crítica relevante do conteúdo intelectual e aprovação final. Lais Fumincelli.
Busca de dados, redação do projeto, revisão relevante do conteúdo intelectual e aprovação final. Vagner José Lopes.

Desenho da revisão, redação do projeto, revisão relevante do conteúdo intelectual e aprovação final. Nen NaLú Alves das Mercês.

Desenho da revisão, redação do projeto, revisão relevante do conteúdo intelectual e aprovação final. Marilene Loewen Wall.

Redação e revisão crítica do manuscrito. Marli Aparecida Rocha de Souza. Aida Maris Peres Lais Fumincelli.Vagner José Lopes. Nen NaLú Alves das Mercês. Marilene Loewen Wall.

Aprovação da versão final do artigo. Marli Aparecida Rocha de Souza. Aida Maris Peres Lais Fumincelli. Vagner José Lopes. Nen NaLú Alves das Mercês. Marilene Loewen Wall.

Responsabilidade por todos os aspectos do conteúdo e a integridade do artigo publicado. Marli Aparecida Rocha de Souza. Aida Maris Peres Lais Fumincelli. Vagner José Lopes. Nen NaLú Alves das Mercês. Marilene Loewen Wall.

\section{EDITOR ASSOCIADO}

Stela Maris Padoin

\section{REFERÊNCIAS}

1. Barufaldi LA, Souto RMCV, Correia RSB, Montenegro MMS, Pinto IS, Silva MMA et al. Gender violence: a comparison of mortality from aggression against women who have and have not previously reported violence. Ciênc. saúde coletiva. 2017;22(9):2929-38. http://dx.doi. org/10.1590/1413-81232017229.12712017.

2. Lira KFS, Barros AM. Violência contra as mulheres e o patriarcado: um estudo sobre o sertão de Pernambuco. Rev Ágora. 2018;22:275-97.

3. Couto VA, Rocha RLS, Ribeiro LML, Silveira AM. Intersetorialidade e ações de combate à violência contra a mulher. Rev. Estud. Fem. 2018;26(2):e45859. http://dx.doi.org/10.1590/1806-9584-2018v26n245859.

4. Trentin D, Vargas MAO, Leal SMC, Vargas CP, Ferreira ML, Neves FB. Women in situations of sexual violence: potentialities and weaknesses of the intersectoral network. Rev Bras Enferm. 2020;73(4):e20190856. http://dx.doi.org/10.1590/0034-7167-2018-0856. PMid:32428122.

5. Horwood J, Morden A, Bailey JE, Pathak N, Feder G. Assessing for domestic violence in sexual health environments: a qualitative study. Sex Transm Infect. 2018;94(2):88-92. http://dx.doi.org/10.1136/ sextrans-2017-053322. PMid:28778979.

6. Meloni VE, Mariana H. Perceptions of professionals in an intersectorial network about the assistance of women in situation of violence. Interface (Botucatu). 2017;21(60):52-62.

7. Ellsberg M, Arango DJ, Morton M, Gennari F, Kiplesund S, Contreras $M$ et al. Prevention of violence against women and girls: what does the evidence say? Lancet. 2015;385(9977):1555-66. http://dx.doi. org/10.1016/S0140-6736(14)61703-7. PMid:25467575.

8. World Health Organization. Global plan of action: to strengthen the role of the health system within a national multisectoral response to address interpersonal violence, in particular against women and girls, and against children. Geneva: WHO; 2016.

9. Cripe SM, Espinoza D, Rondon MB, Jimenez ML, Sanchez E, Ojeda $\mathrm{N}$ et al. Preferences for intervention among Peruvian women in intimate partner violence relationships. Hisp Health Care Int. 2015;13(1):27-37. http://dx.doi.org/10.1891/1540-4153.13.1.27. PMid:25741931.

10. Peters MDJ, Godfrey C, Mclnerney P, Baldini Soares C, Khalil H, Parker D. Scoping reviews. In: Aromataris E, Munn Z, editors. Joanna Briggs Institute Reviewer's Manual [Internet]. Australia: The Joanna Briggs Institute;2017 [citado 2020 abr 2]. Disponível em: https://reviewersmanual. joannabriggs.org/ 
11. Tricco AC, Lillie E, Zarin W, O'Brien KK, Colquhoun H, Levac D et al. PRISMA Extension for Scoping Reviews (PRISMAScR): checklist and explanation. Ann Intern Med. 2018;169(7):467-73. http://dx.doi. org/10.7326/M18-0850. PMid:30178033.

12. Resolução no 254 de 4 de setembro de 2018 (BR). Institui a Política Judiciária Nacional de Enfrentamento à violência contra as Mulheres pelo Poder Judiciário e dá outras providências. Diário Oficial da União [periódico na internet], Brasília (DF), DJE/CNJ no 167/2018, 5 set. 2018, p. 55-9. [citado 2020 abr 2]. Disponível em: https://atos.cnj.jus.br/atos/ detalhar/atos-normativos?documento $=2669$

13. Machisa MT, Christofides N, Jewkes R. Social support factors associated with psychologhical resilience among women survivors of intimate partner violence in Gauteng, South Africa. Glob Health Action 2018;11(Suppl 3):1491114. http://dx.doi.org/10.1080/16549716.2018 .1491114. PMid:30270774.

14. Soares JSF, Lopes MJM. Experiências de mulheres em situação de violência em busca de atenção no setor saúde e na rede intersetorial. Interface (Botucatu). 2018;22(66):789-800. http://dx.doi.org/10.1590/180757622016.0835.

15. Vieira LB, Souza IEO, Tocantins FR, Pina-Roche F. Support to women who denounce experiences of violence based on her social network. Rev Lat Am Enfermagem. 2015 out;23(5):865-73. http://dx.doi. org/10.1590/0104-1169.0457.2625.

16. Albuquerque No L, Moura MAV, Fernandes e Silva G, Penna LHG, Pereira ALF. Mulheres em situação de violência pelo parceiro íntimo: tomada de decisão por apoio institucional especializado. Rev Gaúcha Enferm. 2015;36(no. spe):135-42. http://dx.doi.org/10.1590/1983-1447.2015. esp.54361.

17. Reis MJ, Lopes MHBM, Osis MJD. 'It's much worse tha dying': the experiences off emale victimis of sexual violence. J Clin Nurs. 2017;26(1516):2353-61. http://dx.doi.org/10.1111/jocn.13247. PMid:27140538.

18. Santos WJ, Freitas MIF. Fragilidades e potencialidades da rede de atendimento às mulheres em situação de violência por parceiro íntimo. Rev Min Enferm. 2017;21:e-1048. http://dx.doi.org/10.5935/14152762.20170058.

19. Du Mont J, Kosa D, MacDonald S, Benoit A, Forte T. A comparison of Indigenous and non-Indigenous survivors of sexual assault and their receipt of and satisfaction with specialized health care services. PLoS One. 2017;12(11):e0188253. http://dx.doi.org/10.1371/journal. pone.0188253. PMid:29145501.

20. Mantler T, Wolfe B. A rural shelter in Ontario adapting to address the changing needs of women who have experienced intimate partne violence: a qualitative case study. Rural Remote Health. 2017;17(1):3987. http://dx.doi.org/10.22605/RRH3987. PMid:28298129.

21. Loeffen MJ, Daemem J, Wester FP, Laurant MG, Lo Fo Wong SH, Lagro-Janssen AL. Mentor mother support for mothers experiencing intimate partner violence in family practice: a qualitative study of three different perspectives on the facilitators and barriers of implementation. Eur J Gen Pract. 23(1):27-34. http://dx.doi.org/10.1080/13814788.201 6.1267724 .
22. Evans MA, Feder GS. Help-seeking amongst women survivors of domestic violence: a qualitative study of pathways towards formal and informal support. Health Expect. 2016;19(1):62-73. http://dx.doi. org/10.1111/hex.12330. PMid:25556776.

23. Bahrami M, Shokrollahi P, Kohan S, Momeni G, Rivaz M. Reaction to and coping with domestic violence by Iranian women victims: A qualitative approach. Glob J Health Sci. 2015 jul;8(7):100-9. http:// dx.doi.org/10.5539/gjhs.v8n7p100. PMid:26925908.

24. Wuest J, Merritt-Gray M, Dubé N, Hodgins MJ, Malcolm J, Majerovich JA et al. The process, outcomes, and challenges of feasibility studies conducted in partnership with stakeholders: a health intervention for women survivors of intimate partner violence. Res Nurs Health. 2015 fev;38(1):82-96. http://dx.doi.org/10.1002/nur.21636. PMid:25594917.

25. Sprague C, Woollett N, Parpart J, Hatcher AM, Sommers T, Brown S et al When nurses are also patients: intimate partner violence and the health system as an enabler of women's health and agency in Johannesburg. Glob Public Health. 2016;11(1/2):169-83. http://dx.doi.org/10.1080/17 441692.2015.1027248. PMid:25833744.

26. Pratt-Eriksson D, Bergbom I, Lyckhage ED. Don't ask don't tell: Battered women living in Sweden encounter with healthcare personnel and their experience of the care given. Int J Qual Stud Health Well-being. 2014 fev;9:23166. http://dx.doi.org/10.3402/qhw.v9.23166. PMid:24576461.

27. Malpass A, Sales K, Johnson M, Howell A, Agnew-Davies R, Feder G Women's experiences of referral to a domestic violence advocate in UK primary care settings: a service-user collaborative study. Br J Gen Pract. 2014;64(620):151-8. https://doi.org/10.3399/bjgp14X677527.

28. Ekström V.Violence against women social services support during legal proceedings. Eur J Soc Work. 2014;18(5):661-74. http://dx.doi.org/10 1080/13691457.2014.951600.

29. Cerqueira D, Moura R, Pasinato W. Participação no mercado de trabalho e violência doméstica contra as mulheres no Brasil. Brasília: IPEA;2019. Texto para discussão.

30. Aslan E, Bodur G, Beji NK, Alkan N, Aksoy Ö. Exposure to domestic violence in women living in istanbul and aegean regions: a Turkish sample. Ciênc. saúde coletiva. 2019 Aug 24(8):2835-44. https://doi. org/10.1590/1413-81232018248.22952017.

31. Moreira GAR, Freitas KM, Cavalcanti LF, Vieira LJES, Silva RS Qualificação de profissionais da saúde para a atenção às mulheres em situação de violência sexual. Trab Educ Saúde. 2018 ago;16(3):103955. http://dx.doi.org/10.1590/1981-7746-sol00156.

32. Leite FMC, Silva ACA, Bravim LR, Tavares FL, Primo CC, Lima EFA Victims of violence: perception, complaints and behaviors related to their health. Rev enferm UFPE on line. 2016; ago (Suppl. 6):4854-61. https://doi.org/10.5205/1981-8963-v10i6a11265p4854-4861-2016.

33. Arboit J, Padoin SM, Vieira LB, Paula CC, Costa MC, Cortes LF. Health care for women in situations of violence: discoordination of network professionals. Rev Esc Enferm USP. 2017 abr 3;51:e03207. PMid:28380159. 